the treatment of acute leukaemia. Nests of leukaemic cells may remain in the tissues of patients who had been thought to be in a satisfactory state of remission, and treatment must therefore be persisted with until these nests have been eradicated. This should be the ultimate aim (Mathé, 1965). To achieve this it is necessary that on two successive occasions an extensive search must be made for such nests. This search should be followed up by what Dameshek et al. (1965) have called "a new use of old remedies."

Clinical trials are now in progress in many American centres on the simultaneous use of several antimitotic agents-as yet, it is too early to judge the results (Freireich and Frei, 1964; Freireich et al., 1964).

The clinical procedures that we have adopted in view of our recent results are as follows. The main aim is to induce in our positive cases a state of "true" remission by stepping up the therapeutic dosage which had induced the apparent remission. This concept is based on the hope that the resistance of the nests of leukaemic cells might be due to various extracellular factors, such as anatomical site or vascular distribution, rather than intracellular factors. In all cases we use a treatment that comprises a two-months course for each type of chemotherapy at maximal doses, alternating with a month's treatment with corticosteroids. This intensive therapy is preceded by a systematic irradiation of the meninges at 1,000 rads. The first course of chemotherapy to be given was methotrexate, which is administered both intrathecally and systemically.

The first results that we obtained in the attempt to eradicate the leukaemic cells completely have been encouraging (Mathé, 1965). Full details will be published later.

\section{Summary}

In 31 patients with acute leukaemia who were stated to be in " complete remission," as indicated by a normal peripheral blood and bone-marrow, an extensive histological and cytological investigation was carried out. This investigation comprised the counting of blast cells in the circulating blood, examination of bone-marrow from six sites, examination of the cytology of the C.S.F., an electroencephalogram, renal, hepatic, and testicular biopsies, bone-marrow histology, and $x$-ray examination of the skeleton.

Nests of leukaemic cells were found in 12 patients. None of the tests used gave consistently negative results.

The lessons to be learnt from this study, as regards both prognosis and the treatment designed to eradicate these leukaemic foci, are discussed.

We would like to thank Professors $M$. Derot, R. Küss, and M. Legrain for their co-operation in this clinical study. The investigation was supported by grant CA-05-703-04 from the National Cancer Institute, Public Health Service (Bethesda).

\section{REFERENCES}

Bernard, J., and Mathé, G. (1951). Bull. Soc. méd. Hôp. Paris, 67, 1285. Burchenal, J. H., and Murphy, M. L. (1965). Cancer Res., 25, 1491. Ceoara, B., Slama, R., and Chome, J. (1958). Rev. franç. Étud. clin. biol., 3, 905 .

Dameshek, W., Necheles, T. F., Finkel, H. E., and Allen, D. M. (1965). Blood, 26, 220.

Festing, P. (1962). Rev. franç. Etud. clin. biol., 7, 1105.

Freireich, E. J., and Frei, E. (1964). In Progress in Hematology, edited by C. V. Moore and E. B. Brown, vol. 4, p. 187. Grune and Stratton, New York.

Karon, M., and Frei, E. (1964). Proc. Amer. Ass. Cancer Res., $5,20$.

Mathé, G. (1965). Bull. int. Un. Cancer, 3, 4.

Menghini, G. (1959). Bull. Soc. méd. Hôp. Paris, 75, 798.

Nies, B. A., Bodey, G. P., Thomas, L. B., Brecher, G., and Freireich, E. J. (1965). Blood, 26, 133.

Waitz, R. (1953). Sang, 24, 820

Wells, C. E., and Silver, R. T. (1957). Ann. intern. Med., 46, 439.

\title{
Osteoporosis, Scurvy, and Siderosis in Johannesburg Bantu*
}

\author{
H. C. SEFTEL, $†$ M.B., B.SC., DIP.MED.; C. MALKIN, $\ddagger$ F.R.C.S.ED., M.CH.ORTH. \\ A. SCHMAMAN, $\S$ M.B., D.C.P., M.C.PATH.; C. ABRAHAMS, || M.B., M.MED.PATH., F.F.PATH., M.C.PATH. \\ S. R. LYNCH, M.B.; R. W. CHARLTON,** M.D., B.SC., M.R.C.P.ED.; T. H. BOTHWELL,** M.D., M.R.C.P.
}

[With Special Plate]

brtt. med. F., 1966, 1, 642-646

It is not generally recognized that osteoporosis is a common and disabling disease among middle-aged Bantu in Johannesburg. There have been only two previous studies of the condition. Grusin and Kincaid-Smith (1954) and Grusin and Samuel (1957) were the first to document the disease as a clinical entity, and showed that it was often associated with scurvy. Grobbelaar noted its association with severe siderosis

\footnotetext{
* This work was supported in part by a grant (AMO4912-05) from the National Institutes of Health, United States of America.

t Physician, Department of Medicine, Baragwanath Hospital and University of the Witwatersrand.

‡Orthopaedic Surgeon, Department of Orthopaedics, Baragwanath Hospital and University of the Witwatersrand.

pital and University of the Witwatherent of Pathology, Baragwanath Hospital and South African Institute for Medical Research.
Aftologist, Department

African Institute for Medical Research. II Pathologist, Department of Pathology, University of the Witwatersrand. I Research Fellow, Department of Medicine, University of the Witwatersrand.

** Physician, C.S.I.R. Iron and Red Cell Metabolism Unit, Department
} of Medicine, University of the Witwatersrand. in necropsy material, but in a subsequent post-mortem study of Bantu with varying degrees of siderosis Walker, Strydom, Reynolds, and Grobbelaar (1955) were unable to demonstrate a correlation between the iron content of vertebral bodies and their mineral composition or mineral density. After 1957 interest in the condition lapsed, and unawareness of the existence of such a disorder has resulted in its frequently being misdiagnosed as myeloma, secondary carcinoma, or tuberculosis.

\section{Present Investigation}

In 1962 we began to study the condition again, and the objects of the present paper are to describe the clinical, radiological, biochemical, and pathological characteristics in 32 patients with the disease, to present further data on its association with siderosis and scurvy, and to discuss its possible aetiology and pathogenesis. 
Prevalence.-Though the prevalence of osteoporosis among Johannesburg Bantu is unknown, it appears to be common. At Baragwanath Hospital, which is the principal medical institution serving 800,000 Bantu living in and around Johannesburg, we had little difficulty in collecting the 32 patients in the present series within one year. All were severely osteoporotic, with obvious radiological evidence of vertebral collapse, and the majority were disabled enough to require admission to hospital. It seems likely that many more less severe cases were either treated as out-patients or were not recognized during this period. In fact preliminary results of a prevalence survey now in progress indicate that the majority of patients suffering from the condition are asymptomatic.

Age and Sex.-The ages of the 32 subjects $(26$ males, 6 females) ranged between 30 and 60 years, with a mean of 47. The majority were between 40 and 55. A few patients over the age of 60 who exhibited osteoporosis were also seen, but were omitted from the study, since we wished to exclude senility as a possible aetiological factor. This age and sex distribution contrasts strikingly with that of white osteoporotic patients, since the majority of these are elderly women.

\section{Clinical Presentation}

Most of the male subjects were manual labourers and were working up to the time they became ill. The females were domestic servants or housewives. Backache was one of the principal complaints in all patients, and in the majority it was the only symptom. The pain was felt mostly in the lumbar region, but in some it was over the lower dorsal spine. Frequently it had a girdle distribution or radiated down the legs. In about half of the subjects the backache was spontaneous. In the other half it followed minor trauma, such as slipping while lifting a heavy weight. No patient gave a previous history of major trauma, prolonged immobilization, or steroid therapy.

On examination most of the subjects were disabled, and were unable to walk or stand. Some were even unable to sit or turn in bed. Shortening of the vertebral column was indicated in many patients by a loss of height, or by narrowing of the normal distance between the lower border of the costal margin and the iliac crest. A lumbar or lower dorsal gibbus was sometimes present. Tenderness over the lumbar or lower dorsal spine and spasm of the paravertebral muscles were invariable. A few patients showed muscle weakness or sensory changes in the distribution of one or more lumbar or sacral nerve roots. One subject developed paraplegia, and this case is described in greater detail below.

In three-quarters of the patients firm enlargement of the liver was present, and in one-third the spleen was palpable.

Fourteen subjects showed obvious evidence of scurvy. This usually took the form of haemorrhagic swellings of the gums, or bleeding into the subcutaneous tissues and muscles of the calf or posterior thigh. In addition, some patients had subungual haemorrhages and haemarthroses. One subject had a haemorrhagic pleural effusion.

Apart from scurvy the subjects showed no obvious clinical stigmata of malnutrition. Their diet, high in carbohydrate (mainly maize, bread, and refined sugar), low in animal protein and fat, and low in fresh fruit and vegetables, was similar to that of the general African population. There was, however, one important exception. All the subjects, both male and female, admitted to drinking larger than average quantities of the traditional Bantu beer and its numerous variants for many years. An accurate assessment of the daily consumption was difficult to obtain, but it was of the order of 1 to 2 litres during the week and 1 to 4 litres over week-ends. These brews are prepared from a variety of carbohydrate bases, the commonest being sorghum. They are acid in reaction and readily corrode the crude iron containers, such as petrol drums or paraffin tins, in which they are usually prepared. Their iron content is in consequence very high (mean of about $4 \mathrm{mg} . / 100 \mathrm{ml}$.), and there is now good evidence that they are the principal reason for the varying degrees of iron overload which are so commonly found in Johannesburg Bantu (Walker and Arvidsson, 1953 ; Bothwell et al., 1964b). The brews are also often adulterated with a wide variety of agents, but in the present study it was impossible to assess the relative proportions of adulterated and innocent beer which had been consumed.

None of the osteoporotic subjects showed any evidence of the known metabolic, endocrine, renal, or neoplastic causes of bone diseases.

\section{Radiological Findings}

In all the subjects there was an obvious decrease in density of the dorsal and lumbar spine associated with collapse of the vertebral bodies (Special Plate, Fig. 1). Collapse took the form of wedging, biconcavity (" codfish deformity"), or marked flattening of the bodies (vertebra plana). In most cases between two and six vertebrae were involved. The lumbar spine was most severely affected, followed by the lower dorsal and then the upper dorsal. Neither the spine nor any other part of the skeleton showed evidence of osteomalacia, osteitis fibrosa cystica, or bone malignancy.

In the majority of patients abdominal radiographs revealed a marked and uniform increase in density of the hepatic and splenic shadows. Almost invariably the density of the splenic shadow was equal to or greater than that of the liver. In addition, the liver and spleen were often enlarged. Such findings are usually due to heavy deposits of iron in these organs.

\section{Biochemical Findings}

The serum calcium levels varied between 4 and $5.4 \mathrm{mEq} /$ litre, with a mean of 4.5 . In 24 patients the values were between 4 and 5 , in four between 3.6 and 3.9, and in the remaining four between 5.1 and $5.4 \mathrm{mEq} / 1$. It is possible that some of the low figures reflected low serum albumin levels (see below). Twenty-four-hour urinary excretions of calcium were measured in 16 subjects, usually within one week of admission to hospital. In eight the excretions were within normal limits and varied between 52 and $126 \mathrm{mg}$. In the other eight they were low, measuring 8.0,11.2, 14.5, 17.0, 29.0, 36.2, 47.0 , and $47.6 \mathrm{mg}$. respectively.

All the serum phosphorus estimations fell within the normal range of 2.5 to $4.5 \mathrm{mg} . / 100 \mathrm{ml}$. In 22 patients the levels varied between 3 and $4 \mathrm{mg}$. $/ 100 \mathrm{ml}$. In a further six they were between 2.6 and $2.9 \mathrm{mg} . / 100 \mathrm{ml}$., while in the remaining four the values lay between 4.1 and $4.5 \mathrm{mg} . / 100 \mathrm{ml}$. The phosphorus excretion index of Nordin and Fraser (1960) was estimated in 11 subjects, and all the values were normal.

The serum alkaline phosphatase levels were within the normal range of 4 to $13 \mathrm{King}$-Armstrong units in all except three subjects. These three patients had values of $15.6,20.0$, and 20.6 units. The raised levels were attributed to recent episodes of vertebral collapse.

On protein electrophoresis the mean serum albumin level was $3.0 \mathrm{~g} . / 100 \mathrm{ml}$. (range 2 to 4.1 ), and the mean globulin level was $4.29 \mathrm{~g} . / 100 \mathrm{ml}$. (range 2.8 to 5 ). These figures differ markedly from values in hospitalized white subjects in Johannesburg, but are similar to those found in most hospitalized Bantu. No abnormal protein fractions, such as those seen in myelomatosis, were detected.

Haemoglobin levels were normal except in those subjects exhibiting clinical evidence of scurvy. The majority of the scorbutic subjects had a variable degree of anaemia, but this was rapidly corrected in all patients by the administration of ascorbic acid. 
The levels of serum iron, total iron-binding capacity, and percentage saturation were estimated in all subjects. Results were then compared with those obtained in 41 male in-patients of comparable age who were being treated at Baragwanath Hospital for non-infective conditions. The results are set out in the Table.

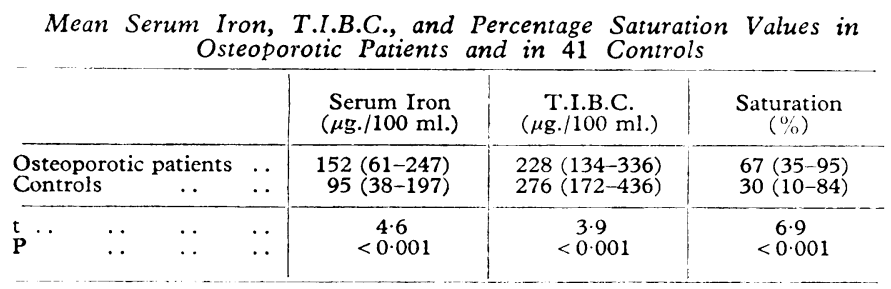

\section{Pathological Findings}

Biopsies of the iliac crest were obtained in 10 subjects. Histological examination of decalcified sections stained with haematoxylin and eosin revealed a considerable decrease in the amount of bone as compared with normal controls in all patients (Special Plate, Figs. 2A and 2B). The trabeculae were decreased in number and markedly attenuated, and the marrow spaces were correspondingly much enlarged. There was no evidence of fibrous replacement, and the structure of the residual bone appeared to be normal. In particular, there was no evidence of excess osteoid tissue, neoplasia, or an increase in the number of osteoclasts. Osteoblasts, which were never numerous, were often very scanty or entirely absent. The borders of the bony trabeculae were generally smooth and without evidence of increased osteoclasis. Within the widened marrow spaces heavy deposits of haemosiderin were observed, but there was no stainable iron in the bony trabeculae.

The degree of siderosis was assessed further in 16 males and 2 females by histological examination of liver biopsy specimens. When the degrees of siderosis were graded by means of the criteria described by Bothwell and Bradlow (1960) 17 were found to be severely siderotic and one moderately so. Coarse granules or masses of haemosiderin were present in the portal tracts, and in the parenchymal and Kuppfer cells (Special Plate, Fig. 3). The results of previous studies indicate that the concentrations of iron in the liver are almost invariably greater than $1 \%$ dry weight when such histological findings are present (Bothwell and Bradlow, 1960 ; Bothwell and Isaacson, 1962). In addition to the iron deposits most specimens exhibited varying degrees of portal fibrosis, but only two had cirrhosis.

Two male subjects came to necropsy. The cause of death in the first patient, who was aged 38 years, was not certain but was probably hepatic failure. The second, aged 53, presented with pain over the lower dorsal spine, and $x$-ray examination revealed wedging of the fourth dorsal and first and third lumbar vertebrae. The pain responded to rest in bed and aspirin, and he was discharged after being fitted with a spinal brace. He was not seen again until 14 months later, when he suddenly developed paraplegia and loss of all sensation, except position sense, below D10. On $x$-ray examination the eighth dorsal vertebral body was seen to be completely collapsed, while wedging of variable degree was noted in the fourth, sixth, seventh, ninth, and eleventh dorsal vertebrae and the upper fourth lumbar vertebra. Myelography revealed a complete block at the level of the eighth dorsal vertebra. At laminectomy it was found that collapse of the eighth and adjacent dorsal vertebral bodies had resulted in compression of the spinal cord. After resection of the eighth and ninth dorsal laminae most of the neurological signs disappeared within a few days. Two months later, however, this patient developed a volvulus of the sigmoid colon and died.

At necropsy both subjects showed evidence of severe osteoporosis and severe siderosis. All the vertebrae, ribs, sternum, and pelvis were extremely porous and brittle. The ribs could easily be snapped between the thumb and index finger. The signs of vertebral-body collapse noted radiologically were confirmed. The marrow was distinctly brown in colour, due to very heavy deposits of haemosiderin. Histological sections of the vertebrae, ribs, and iliac crest showed a marked reduction in the amount of cortical bone. The medullary trabeculae were decreased in number and very thin, appearing as a fine tracery in a matrix of siderotic marrow. The bone itself appeared to be normal.

The liver and spleen were enlarged (weighing 1,710 g. and $350 \mathrm{~g}$. respectively in the first case and $3,480 \mathrm{~g}$. and $670 \mathrm{~g}$. in the second) and of a deep rust colour. The duodenum, upper part of the jejunum, and abdominal lymph nodes were similarly coloured. In all these tissues histological examination revealed the presence of very heavy deposits of haemosiderin. The chemical concentrations of iron present in the liver and spleen were estimated in the second case with the following results: liver 3.4 g. $\%$ dry weight ; spleen 5.7 g. \% dry weight. Both livers showed an increase in periportal fibrous tissue, but there was no evidence of true cirrhosis.

Varying amounts of haemosiderin were observed in the interstitial tissue of most organs of the body, but only small deposits were present in the parenchymal cells of the pancreas, the adrenal, thyroid, and pituitary glands, and within myocardial fibres. The excessive deposits of iron in these cases were therefore mainly located in the liver, reticulo-endothelial system, and small intestine. A distribution of this type is typical of that found in the majority of siderotic Bantu in Johannesburg (Higginson et al., 1953).

\section{Treatment and Course}

Though these aspects have not yet been studied systematically, certain preliminary comments can be made. The signs of acute scurvy have responded promptly to ascorbic acid in doses of 100 to $500 \mathrm{mg}$. daily, and have disappeared within one to three weeks. The radiological signs of osteoporosis have remained unchanged on treatment with ascorbic acid and calcium lactate, singly or in combination. This, however, is not surprising, since no patient has been on treatment for more than six months, and radiological improvement would not be anticipated after such a short period even if therapy were effective. Most patients have exhibited marked symptomatic improvement in hospital, and pain, even when associated with marked disability, has of ten responded to bed-rest alone. Analgesics more potent than aspirin have rarely been required. The majority of patients have become ambulant within two to three weeks with simple physiotherapy and a spinal brace of the Robert Jones type, but their range of physical activity has remained restricted and most of them have been unable to resume their work as manual labourers.

\section{Discussion}

An association between the occurrence of osteoporosis and scurvy in middle-aged Bantu was originally noted by Grusin and Samuel (1957). They found that $69 \%$ of the osteoporotic subjects in their series were scorbutic, or had been scorbutic in the past. In addition, it was shown that $19 \%$ of patients presenting with classical acute scurvy exhibited severe osteoporosis. While the association between the two conditions was confirmed in the present study, its strength was found to vary with the season. As in other populations, most cases of scurvy in Johannesburg Bantu occur in the late winter and springthat is, between July and October. Of the 14 subjects with osteoporosis who presented during this period $71 \%$ were scorbutic, as compared with an incidence of only $22 \%$ in the 18 patients who were seen in the remaining eight months of the year. In the general hospital population aged between 30 
H. C. SEFTEL ET $A L$. : OSTEOPOROSIS, SCURVY, AND SIDEROSIS IN JOHANNESBURG BANTU

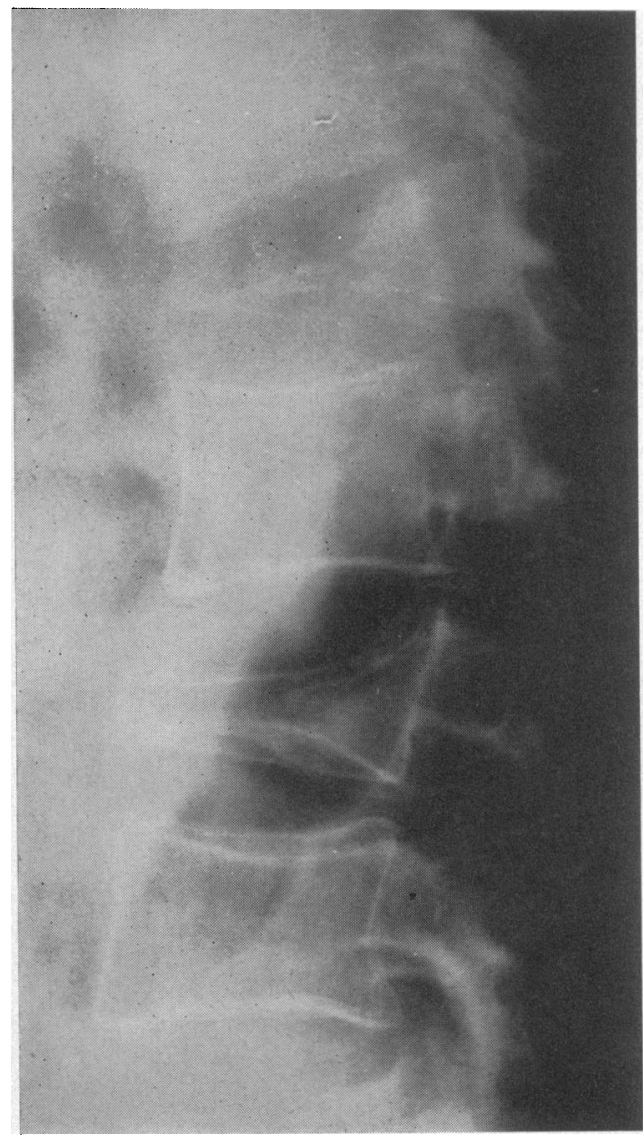

FIG. 1

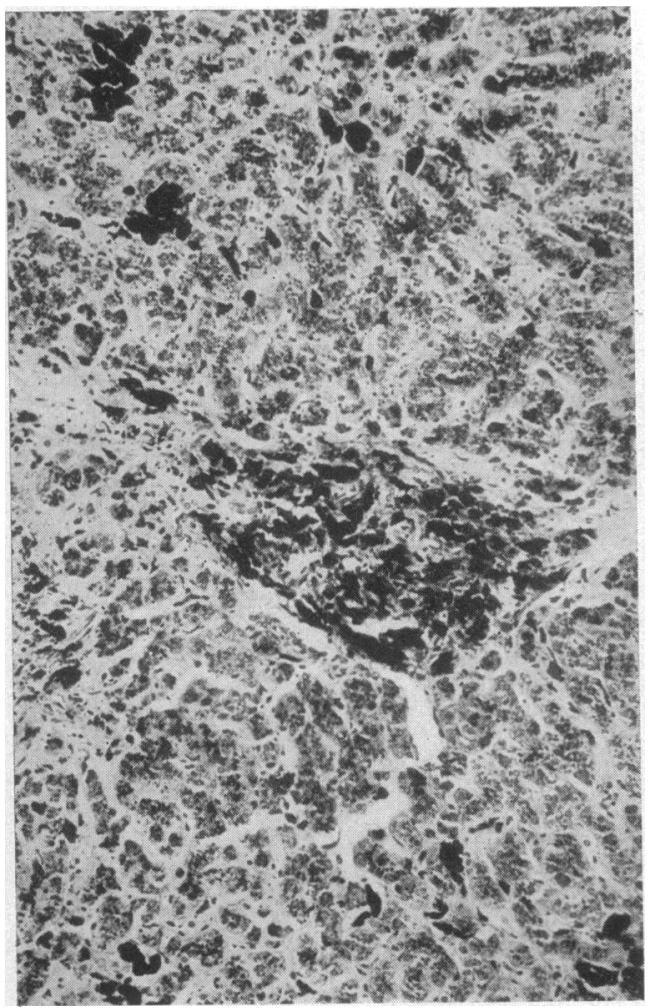

FIG. 3.-Section of liver showing heavy deposits of iron in parenchymal cells, Kupffer cells, and portal tracts. (Perls's stain. $\times 100$.)

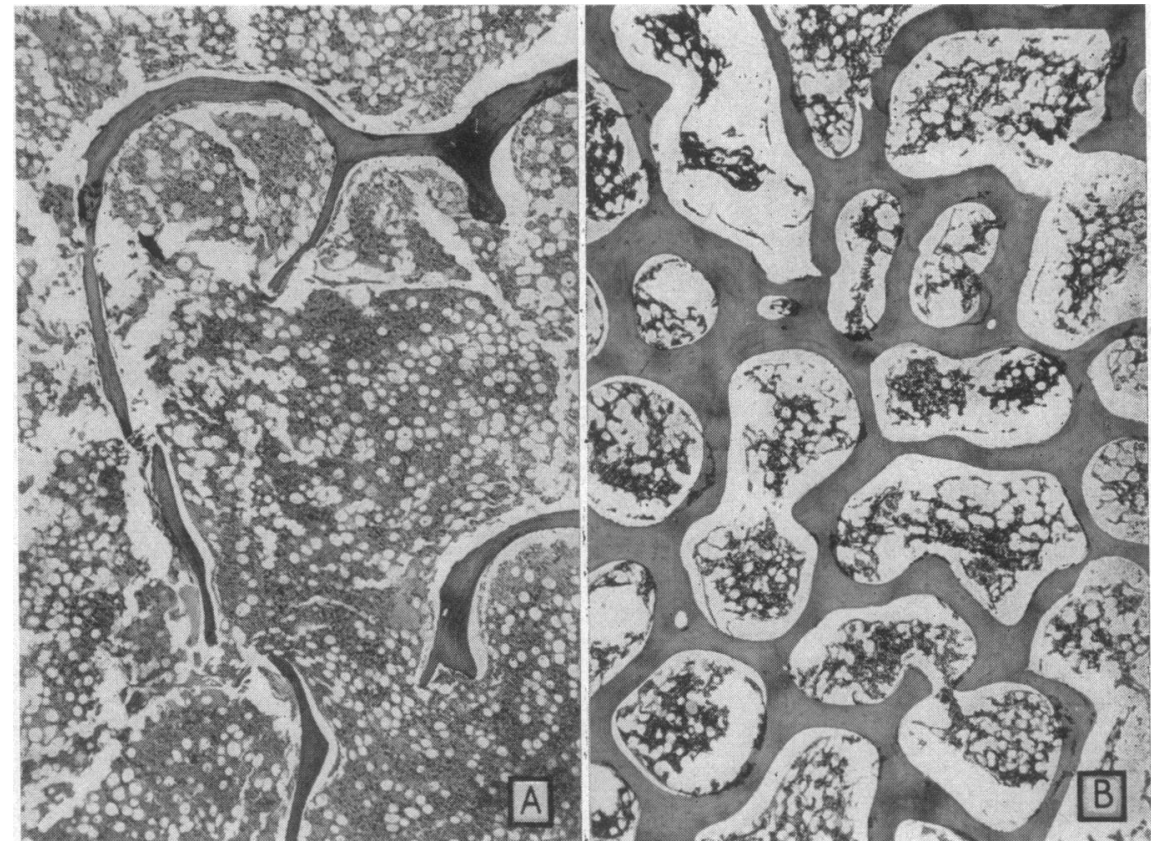

FIG. 2

FIG. 1.-X-ray plate of the lumbar spine of a Bantu male with severe siderosis, showing a marked diminution in bone density and vertebral collapse.

Fig. 2A.-Section of iliac crest bone from osteoporotic subject showing thin trabeculae and widened marrow spaces. (H. and $\mathrm{E} . \quad \times 18$.)

FIG. 2B.-Section of iliac crest bone from control subject showing normal trabeculae and marrow spaces. (H. and E. $\times 18$.)

\section{E. DENT AND L. WATSON: HYPERPARATHYROIDISM AND SARCOIDOSIS}

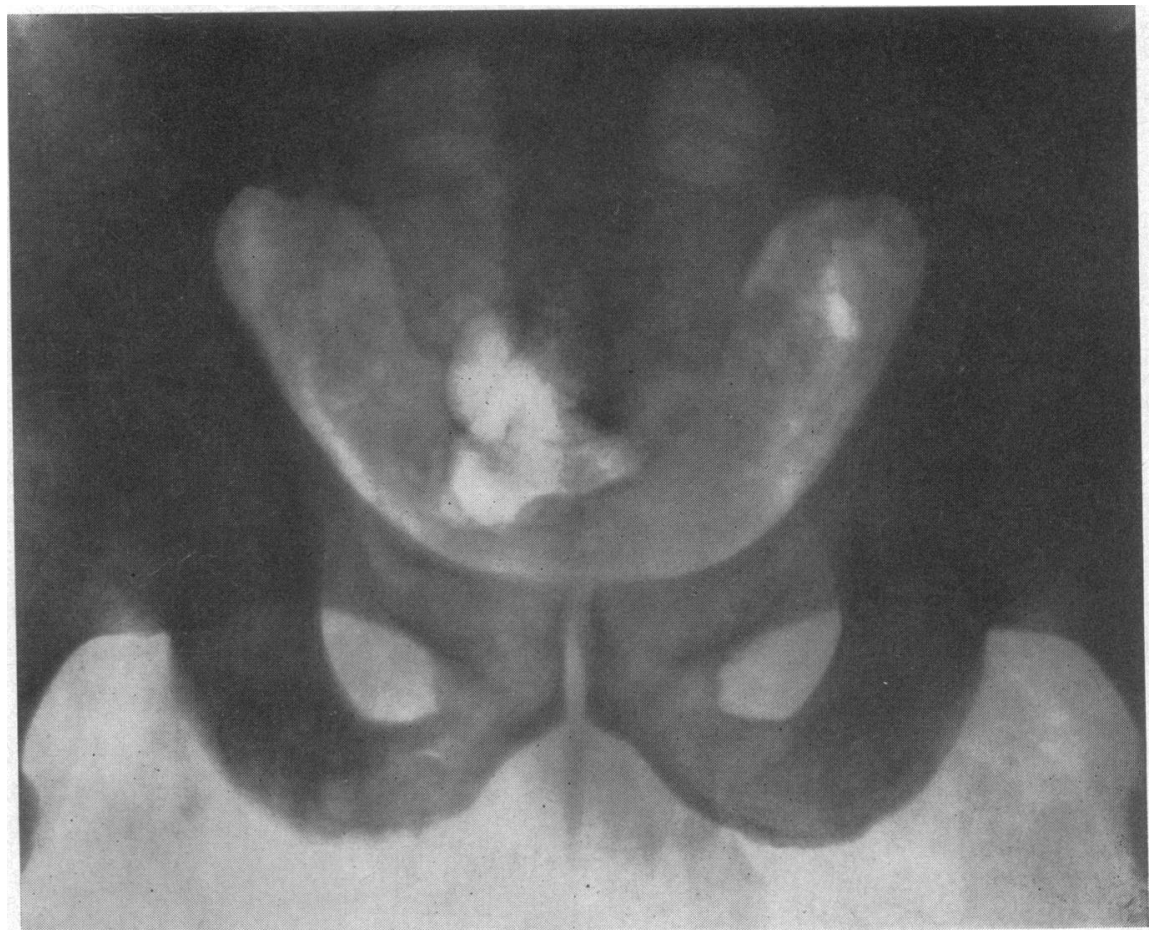

$X$-ray film of pelvis taken on 12 December 1964. Note the abnormal appearance of the

$\mathrm{X}$-ray film of pubic ramus and ischium, discussed further in the text.

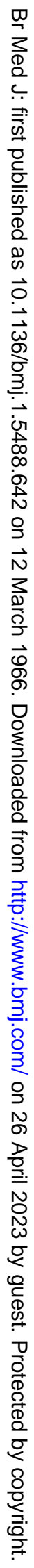


and 60 years the maximum prevalence of acute scurvy never exceeds $1 \%$ at any time of the year.

These various observations all support the thesis that there is a relationship between the occurrence of osteoporosis in middle-aged Bantu and scurvy. To prove a similar association between osteoporosis and severe siderosis is more difficult, since varying degrees of iron overload are so common in adult Bantu (Higginson et al., 1953 ; Bothwell and Isaacson, 1962). There are, however, several pieces of evidence to indicate that this association is a real one. In the first place it has been shown previously that scurvy in Johannesburg Bantu occurs almost exclusively in middle-aged male subjects who consume large amounts of the local brews, and whose livers are invariably heavily siderotic on biopsy or at necropsy (Bothwell et al., 1964a). These observations were confirmed and supplemented in the present investigation.

All the osteoporotic subjects were heavy drinkers, and the male-to-female ratio of between 4 and 5 to 1 was the same as that observed for severe siderosis in a previous pathological study (Bothwell and Isaacson, 1962). Further clinical evidence compatible with marked iron overload was the occurrence of firm hepatomegaly in $70 \%$ of patients and splenomegaly in $30 \%$. Corresponding figures for 100 matched hospital controls were $21 \%$ and $6 \%$ respectively. In addition, the mean serum iron level and percentage saturation of the iron-binding capacity were considerably higher than those found in a matched group of non-osteoporotic in-patients (see Table). Finally, direct histological evidence of severe hepatic siderosis was obtained in 19 of the 20 specinens examined, the remaining one being moderately siderotic. The criteria used for grading were those previously described from this laboratory (Bothwell and Bradlow, 1960 ; Bothwell and Isaacson, 1962). It has been shown that the appearances of severe siderosis are almost invariably associated with chemical concentrations of iron in the liver of more than $1 \%$ dry weight. Such concentrations have been found in less than $50 \%$ of Bantu males in the same age groups as the osteoporotic subjects. The fact that both the females on whom liver biopsies were done in the present study showed evidence of severe siderosis is also of significance, since such findings occur in less than $10 \%$ of the comparable female population (Bothwell and Isaacson, 1962).

When all this evidence is considered there can be little doubt that the association between osteoporosis and severe siderosis is a real one. Before discussing the possible significance of this relationship it is perhaps relevant that there are other isolated reports of the two conditions occurring together. For example, beef cattle in an area of New Zealand where the iron content of the water is exceptionally high (up to $20 \mathrm{mg} . / 100 \mathrm{ml}$.) develop a form of siderosis similar to that seen in the Bantu. In addition, many of the severely siderotic animals develop osteoporosis, which is most marked in the vertebrae, sternum, and ribs (Hartley et al., 1959). Osteoporosis has also been reported in six French subjects with haemochromatosis (Delbarre, 1960). It is possible that the aetiology of the condition in these patients was similar to that in the Bantu, since there is recent evidence that haemochromatosis in white subjects sometimes results from excessive consumption of wines containing large amounts of iron (MacDonald, 1964). However, hypercalciuria was a feature of Delbarre's patients, while the urinary calcium excretions were normal or low in the present study.

Finally, there is the obscure disorder known as Kaschin-Beck disease (Hiyeda, 1939). The condition is characterized by symmetrical joint deformities with shortening of the long bones. At necropsy the main features are extensive siderosis of many organs, thinning of the bone cortex, and degeneration of joint cartilage. In Manchuria the incidence of the condition has been correlated with a high iron content of the well-water used for drinking. Recently Russian workers in the Transbaikal area of Siberia have reported the isolation of a fungus, Fusaria sporotrichiella, from affected joints in individuals with a similar type of presentation (Nesterov, 1964), but the relation of these findings to those described by Hiyeda (1939) is still not clear.

\section{Some Possibilities}

In attempting to explain the significance of the association between osteoporosis, scurvy, and severe siderosis, several possibilities merit consideration. In the first place it is conceivable that all three may result directly from excessive consumption of the local alcoholic brews. This hypothesis is supported by recent work demonstrating that the mean bone density of chronic alcoholic subjects at necropsy is significantly less than that of non-alcoholic controls of similar age (Saville, 1965). By Western standards the average Bantu diet is low in animal protein, calcium, and ascorbic acid, and the diets of heavy drinkers might be expected to be even lower in respect of these nutrients. Such an explanation would be sufficient to account for the development of osteoporosis, since not only are deficiencies of protein and ascorbic acid well-recognized causes of the condition (Fourman, 1960) but there is recent eviderice to indicate that lack of calcium can also be a cause (Nordin, 1961). On this basis the osteoporosis would result from lack of one or more of the three nutrients, the scurvy from ascorbic acid deficiency, and the severe siderosis would simply reflect the large amounts of iron consumed in the brews.

There are, however, certain considerations which make this explanation appear unlikely. Though the dietary habits of the patients in the present study were assessed by the method of questioning only, they did not seem to differ significantly from those of the general population, except in so far as beer consumption was concerned. It should be stressed that the osteoporotic subjects were not alcoholics in the generally accepted sense. They were social, not pathological, drinkers, and most of them were in regular employment when they became ill. Furthermore, the alcohol concentration of the brews is usually only about $3 \%$, while their content of protein and B-complex vitamins is appreciable (Novellie, 1964). In addition, apart from scurvy, the osteoporotic subjects were not obviously malnourished, and their serum protein levels were similar to those of the general hospital population. It therefore seems unlikely that the syndrome is simply the result of malnutrition associated with excessive alcohol consumption.

\section{Alternative Explanations}

Other explanations for the present findings depend on the high iron content of the alcoholic drinks and the resultant severe siderosis. There are at least three ways in which iron overload might theoretically lead to osteoporosis. It might damage organs or tissues concerned with bone formation, it might impede calcium absorption, or it might interfere with the metabolism of ascorbic acid. These possibilities are considered separately.

Severe liver disease with impaired protein synthesis has been mentioned as a cause of osteoporosis (Fourman, 1960). In the present study two of the patients were cirrhotic and a third probably died from liver failure. In the majority, however, hepatic function appeared to be adequate. Moreover, no patient showed any evidence of diabetes or other hormonal deficiency. It therefeore seems unlikely that the osteoporosis was secondary to liver disease or endocrine disorder.

A second way in which iron overload might give rise to osteoporosis is by interfering with calcium absorption. Studies on isolated rat intestinal preparations have shown that high concentrations of iron in the lumen can diminish calcium absorption (Manis and Schachter, 1964). In addition, it is possible that the heavy deposits of haemosiderin in the epithelium and lamina propria of the duodenum and jejunum, which are a constant feature of severely siderotic Bantu, may have a similar 
effect. Even a small decrease in absorption would be important, since the calcium intake in adult Bantu is usually less than $500 \mathrm{mg}$. daily (Walker, 1965). While the low levels of calcium in the serum and urine of a number of our osteoporotic subjects would be compatible with diminished absorption from the gut, as yet no direct confirmatory evidence for this has been obtained.

The possibility that the osteoporosis may be the result of chronic ascorbic acid deficiency, and that this deficiency is in turn a function of the severe siderosis, deserves consideration. The association of osteoporosis with scurvy is well recognized, and probably relates to the role of ascorbic acid in the formation of collagen and hence new bone (Vilter, 1954). In Johannesburg scurvy occurs almost exclusively in Bantu adults with severe siderosis, and is extremcly rare in infants, even when gross malnutrition is present (Trowell, 1960). This suggests that siderosis may play a part in the production of the scurvy. Evidence in favour of this thesis was first obtained in 1962 by Schulz and Swanepoel, who reported the results of ascorbic acid "saturation" tests in two Bantu patients with severe siderosis and scurvy. They found that urinary excretion of ascorbic acid remained very low after repeated administration of large oral doses of the vitamin, and in one patient this was also noted after parenteral loading. It is known from in vitro studies that ferric iron accelerates the oxidative catabolism of ascorbic acid (Mazur et al., 1960), and Schulz and Swanepoel therefore suggested that the massive ferric deposits in severely siderotic Bantu might act likewise. If this were so then it would be anticipated that ascorbic-acid loading would be followed by an increased passage of its oxidation products in the urine.

Recently we have confirmed and extended the observations of Schulz and Swanepoel (1962) by showing that ascorbic-acid loading of siderotic Bantu is associated not only with a low urinary excretion of the vitamin but also with an increased excretion of the end-product oxalic acid (Seftel et al., 1964). If ascorbic-acid deficiency does play a part in the production of osteoporosis in the Bantu it will be the first time that such an association has been established in adults. Previously it has been documented adequately only in children and experimental animals (Vilter, 1954 ; Höjer, 1923).

\section{Summary}

The clinical, radiological, biochemical, and pathological features of 32 Bantu patients with severe spinal osteoporosis are described. The condition has been found to differ strikingly from the usual forms of osteoporosis encountered in white subjects. Firstly, the majority of the affected patients were middle-aged men. Secondly, a significant proportion exhibited the features of classical acute scurvy. Thirdly, the condition was almost invariably associated with severe siderosis. Possible reasons for the association between osteoporosis, scurvy, and siderosis are discussed.

We wish to thank the Superintendent of Baragwanath Hospital for permission to publish, the Director of the South African Institute for Medical Research for facilities granted, and Mr. M. Ulrich for the photomicrographs.

[Reprint requests to be addressed to Dr. H. Seftel, Department of Medicine, Medical School, Hospital Street, Johannesburg, South Africa.]

\section{REFERENCES}

Bothwell, T. H., and Bradlow, B. A. (1960). Arch. Path., 70, 279. Jacobs, P., Keeley, K. J., Kramer, S, Seftel, H. C., and Zail, S. (1964a). Brit. F. Haemat., 10, 50.

and Isaacson, C. (1962). Brit. med. F., 1, 522

Seftel, H. C., Jacobs, P., Torrance, J. D., and Baumslag, N. 1964b). Amer. 7. clin. Nutr., 14, 47

Delbarre, F. (1960). Sem. Hôp. Paris, 36, 576.

Fourman, P. (1960). Calcium Metabolism and the Bone. Blackwell, Oxford.

Grusin, H., and Kincaid-Smith, P. S. (1954). Amer. f. clin. Nutr., 2, 323.

- and Samuel, E. (1957). Ibid., 5, 644.

Hartley, W. J., Mullins, J., and Lawson, B. M. (1959). N.Z. vet. F., 7, 99.

Higginson, J., Gerritsen, T., and Walker, A. R. P. (1953). Amer. F. Path., $29,779$.

Hiyeda, K. (1939). Fap. F. med. Sci., 4, 91

Hö er, J. A. (1923). Acta paediat. (Uppsala), 3, Suppl., p. 48

MacDonald, R. A. (1964). Hemochromatosis and Hemosiderosis.

Manis, J., and Schachter, D. (1964). Amer. F. Physiol., 207, 893.

Manis, J., and Schachter, D. (1964). Amer. F. Physiol., 207, 893. Nesterov, A. I. (1964). Arthr. and Rheum., 7, 29.

Nordin, B. E. C. (1961). Lancet, 1, 1011.

- and Fraser, R. (1960). Ibid., 1, 947.

Novellie, L. (1964). In Johannesburg Kaffir Beer Research ProjectPsychological, Nutritional and Sociological Studies of Kaffir Beer. South African Council for Scientific and Industrial Research, Pretoria.

Saville, P. D. (1965). 7. Bone ft Surg., 47 A, 492.

Schulz, E. J., and Swanepoel, H. (1962). S. Afr. med. F., 36, 367.

Seftel, H. C., Charlton, R W., Jacobs, P., and Bothwell, T. H. (1964). S. Afr. F. med. Sci., 29, 97.

Trowell, H. C. (1960). Non-infective Disease in Africa. Arnold, London.

Vilter, R. W. (1954). In The Vitamins, edited by W. H. Sebrell and R. S. Harris, vol. 1. Academic Press, New York.

Walker, A. R P. (1965). Amer. F. clin. Nutr., 16, 327.

and Arvidsson, U. B. (1953). Trans, roy. Soc. trop. Med. Hyg., $47,536$.

Strydom, E. S. P., Reynolds, P. A., and Crobbelaar, B. G. (1955).

S. Afr. F. Lab. clin. Med., 1, 254.

\title{
Hyperparathyroidism and Sarcoidosis
}

\author{
C. E. DENT,* M.D., F.R.C.P.; LYAL WATSON,* M.B., F.R.A.C.P.
}

[With Special Plate]

Brit. med. F., 1966, 1, 646-649

The characteristic clinical features of a raised plasma calcium are now well known and in consequence the diagnosis of hypercalcaemia is being made with increasing frequency. Cases have also been described in which it has been found more or less by accident in individuals who are completely free of hypercalcaemic symptoms or signs. This happened in the case reported here.

Whatever the mode of presentation the cause of the hypercalcaemia can usually be established with certainty. Difficulty

* Member of the Medical Unit, University College Hospital, London. arises, however, in patients who are found to have more than one of the known possible causes of a raised plasma calcium. We referred to this problem recently when we reported the case of a patient who proved to have both primary carcinoma of the cervix uteri and primary hyperparathyroidism due to a parathyroid adenoma (Dent and Watson, 1964), and we added that this complex situation seemed to have occurred more often than it should.

Reviewing his experience in the first 80 patients with primary hyperparathyroidism treated at University College Hospital, one of us (Dent, 1962) listed the other diseases found associated 